\title{
Pengaruh Penggunaan Media Audio Visual Terhadap Keterampilan Smash Bulutangkis
}

\author{
${ }^{1}$ Asep Akbarudin $\bowtie$, ${ }^{2}$ Kurniawan Arby \\ ${ }^{1}$ STKIP Subang \\ 2STKIP Pasundan \\ 1asep.akbaruddin@gmail.com, ${ }^{2}$ kurniawan.arby@gmail.com
}

\begin{abstract}
ABSTRAK
Tujuan dari penelitian ini adalah ingin mengetahui pengaruh penggunaan media audio visual terhadap keterampilan smash dalam pembelajaran bulutangkis di SMP Negeri 2 Dayeuhkolot, Metode yang digunakan dalam penelitian ini adalah metode eksperimen dengan desain penelitian one shoot case study. Populasi pada penelitian ini adalah seluruh siswa kelas IX yang mengikuti pembelajaran pendidikan olahraga di SMP Negeri 2 Dayeuhkolot Kabupaten Bandung yang berjumlah 395 orang dan yang dijadikan sampel penelitian ini adalah 40 orang siswa kelas IX-J. Instrumen yang digunakan dalam penelitian ini tes keterampilan pukulan smash dalam bulutangkis. Teknik pengolahan dan analisis data menggunakan program SPSS 23. Adapun hasil penelitiannya rata-rata nilai siswa sebesar 19,20 yang berarti pengaruh pembelajaran media audio visual terhadap keterampilan smash bulutangkis tersebut baik. Dengan persentase 35\% cukup, 57,50\% baik dan 7,5\% baik sekali. Dari hasil penelitian diketahui bahwa penggunaan media audio visual memiliki pengaruh yang baik terhadap keterampilan smash bulutangkis dengan persentse $57,5 \%$.
\end{abstract}

Kata Kunci: Media Audio Visual, Keterampilan Smash, Bulutangkis

\section{ABSTRAC}

The purpose of this study was to determine the effect of using audio visual media on smash skills in learning badminton at SMP Negeri 2 Dayeuhkolot. The method used in this study was an experimental method with a one shoot case study research design. The population in this study were all students of IX's class who participated in learning sports education at SMP Negeri 2 Dayeuhkolot of Bandung Regency, amounting to 395 people and the samples of this study were 40 students of IX-J's class. The instrument used in this research is a smash skill test in badminton. The data processing and analysis techniques used the SPSS 23 program. The results of the research showed that the average score of the students was 19.20 which means that the effect of learning audio-visual media on badminton smash skills is good. With a percentage of $35 \%$ is sufficient, $57.50 \%$ is good and $7.5 \%$ is very good. From the research results it is known that the use of audio-visual media has a good effect on badminton smash skills with a percentage of $57.5 \%$.

Keyword: Audio Visual, Smash Skill, Badminton

Alamat Korespondensi: STKIP Subang

$\bowtie$ Email: asep.akbaruddin@gmail.com

(C) 2020 STKIP Pasundan ISSN 2721-5660 (Cetak) ISSN 2722-1202 (Online) 


\section{PENDAHULUAN}

Pendidikan adalah usaha sadar dan sistematis, yang dilakukan oleh orang orang yang diserahi tanggung jawab untuk mempengaruhi peserta didik agar mempunyai sifat dan tabiat sesuai dengan cita-cita pendidikan (Muhson, 2010). Peningkatan mutu pendidikan formal di sekolah dipengaruhi oleh keberhasilan proses belajar mengajar. Proses belajar mengajar tersebut dipengaruhi oleh berbagai komponen yang mendukung dan saling berkaitan satu sama lain yaitu guru, siswa, media, dan metode pembelajaran. Jadi diantara komponen tersebut masing-masing mempunyai peranan yang mempengaruhi optimalnya proses pembelajaran mutu pendidikan dapat tercapai dengan hasil yang baik dan berkualitas (Sobarna, Akhmad. Aditya Prasetyo, dicky Gunawan, 2016).

Pendidikan jasmani merupakan alat pendidikan yang menggunakan aktivitas fisik dan olahraga sebagai media untuk mencapai tujuan-tujuan pendidikan Juliantie, Subroto, \& Yudiana (2012). Pendidikan Jasmani, Olahraga dan Kesehatan (PJOK) merupakan salah satu mata pelajaran yang wajib diberikan di suatu jenjang sekolah tertentu mulai dari tingkat pendidikan dasar sampai pada tingkat pendidikan menengah atas (SMA). Mata pelajaran ini diharapkan dapat memberikan kontribusi yang baik dalam upaya mengembangankan aspek fisik, mental, sosial dan emosional dalam rangka mencapai tujuan sistem pendidikan (Hambali, 2018). Ballou mengatakan "Bulutangkis merupakan permainan yang banyak menggunakan kemampuan fisik dengan gerakan yang cepat dan pukulan keras yang dilakukan dalam waktu beberapa detik diantara reli-reli panjang" (Subarjah, 2010). Dalam kaitannya dengan keterampilan dasar memukul shuttlecock, seseorang sudah dapat bermain bulutangkis apabila dapat melakukan beberapa keterampilan dasar teknik memukul shuttlecock, yang terdiri atas servis, lob, drive, netting, dropshot, dan smash (Subarjah, 2010).

Dalam metodologi pengajaran ada dua aspek yang paling menonjol yaitu metode mengajar dan media pembelajaran sebagai alat bantu mengajar. Media adalah segala sesuatu yang memuat pesan atau bahan ajar untuk ditransmisikan melalui suatu alat tertentu (Juliantie dkk, 2012). Media audio visual merupakan salahsatu alternatif untuk membantu siswa dalam mempermudah memahami materi yang dipelajari, penggunaan media audio visual sangat diperlukan dalam upaya memperjelas dan memperluas pengertian kepada siswa. Diharapkan media audio visual dapat menarik dan mengarahkan perhatian siswa untuk berkonsentrasi kepada isi pembelajaran. Hal ini dirasa penting untuk mengingkatkan hasil belajar siswa dikelas. Sehingga masalah pembelajaran yang dialami siswa dapat teratasi dengan meningkatnya hasil belajar dan menghidupkan suasana pembelajaran lebih menarik.

Namun sayangnya, dari hasil observasi dilapangan guru mata pelajaran pendidikan jasmani masih menggunakan metode ceramah dan kurang memanfaatkan penggunaan media audio visual untuk proses pembelajaran. Dengan menggunakan media audio visual siswa dituntut untuk 
memahami gerakan keterampilan smash pada pembelajaran bulutangkis, kemudian siswa mengaplikasikannya dalam suatu proses pembelajaran berupa latihan. Hal tersebut akan membuat siswa lebih mudah memahami dan mendalami materi yang berdampak kepada hasil belajar yang akan dicapai siswa.

\section{METODE}

Metode yang digunakan dalam penelitian ini adalah menggunakan metode eksperimen. Penelitian eksperimen merupakan metode penelitian yang digunakan untuk mencari pengaruh perlakuan tertentu terhadap yang lain dalam kondisi yang terkendali (Sugiyono, 2015).

\section{Subjek Penelitian}

Penelitian ini dilakukan kepada seluruh siswa kelas IX-J SMP Negeri 2 Dayeuhkolot Kabupaten Bandung sebanyak 40 orang. Teknik pengambilan subjek atau sampel penelitian menggunakan one shoot case study.

\section{Prosedur Penelitian}

Agar proses penelitian pada metode eksperimen lebih terarah, sehingga dibuat desain penelitian, untuk desain penelitian yang diterapkan dalam penelitian ini yaitu menggunakan one shoot case study. Artinya dimana dalam desain penelitian sampel diberikan perlakuan kemudian dilakukan tes atau diobservasi hasil kinerjanya, tanpa adanya tes awal terlebih dahulu. Desain penelitiannya dapat digambarkan sebagai berikut:

$$
X \rightarrow 0
$$

Gambar 1. Desain Penelitian One Shoot Case Study

Keterangan:

$\mathrm{X} \quad=$ Treatmen (Perlakuan) dengan menggunakan audio visual

o $\quad=$ Tes Keterampilan Smash Bulutangkis

Untuk prosedur perlakuan diberikan sebanyak empat kali pertemuan, dengan 3 kali pertemuan digunakan untuk memberikan perlakuan dan satu kali pertemuan untuk dilakukan tes. Adapun perlakuan yang diberikan kepada siswa berupa pembelajaran power point, video dan gambar.

\section{Instrumen Penelitian}

Instrumen yang digunakan dalam penelitian ini adalah tes keterampilan smash permainan bulutangkis. Instrumen tes ini diambil dari buku Nurhasan (2013), dimana prosen penilaian merujuk pada proses gerakan siswa. Berikut penjelasan mengenai instrumen yang akan dipakai untuk penelitian Prosedur : Siswa mlakukan gerakan memukul smash mulai dari gerakan 
awalan, Pelaksanaan sampai gerakan lanjutan sebnyak tiga kali pengulangan dan diambil skror tertinggi.

\section{Analisi Data}

Teknik analisis data pada penelitian ini dilakukan dengan menggunakan IBM SPSS Statistics 23 dan Microsoft Excel 2013, dengan tahapan perhitungan sebagai berikut : 1). Melakukan perhitungan rata-rata, 2). Melakukanperhitungan simpangan baku, 3). Melakukan normalitas dengan menggunakan IBM SPSS Statistics 23. 4). Melakukan uji hipotesis dan uji persentase.

\section{HASIL PENELITIAN}

\section{Deskripsi Data}

Penelitian dilakukan selama 4 kali pertemuan yang terdiri dari 3 kali pertemuan di berikan perlakuan pembelajaran dan 1 kali pertemuan test. Data yang terkumpul dari hasil test berupa data kuantitatif. Pengolahan data kuantitatif menggunakan bantuan Software Microsoft Excel 2013 dan IBM SPSS Statistics 23.

Tabel 1. Rekapitulasi Nilai Keterampilan Smash Bulutangkis

\begin{tabular}{cccccc}
\hline Variabel & $\mathbf{N}$ & $\overline{\boldsymbol{x}}$ & S.B & Min. & Max. \\
\hline $\begin{array}{c}\text { Smash } \\
\text { Bulutangkis }\end{array}$ & 40 & 19,20 & 4,165 & 13 & 28 \\
\hline
\end{tabular}

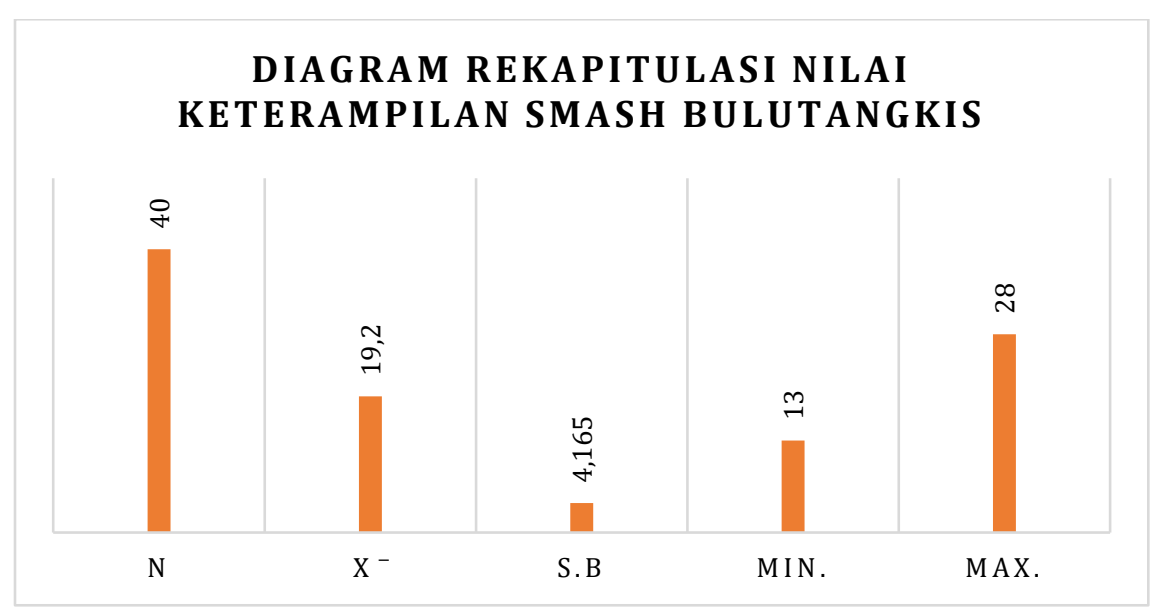

Gambar 2. Diagram Rekapitulasi Nilai Keterampilan Smash Bulutangkis

Berdasarkan hasil test keterampilan smash bulutangkis pada Tabel 1. Dan Gambar 2. Menunjukkan bahwa kemampuan siswa kelas IX-J dari jumlah 40 orang siswa di Sekolah SMP Negeri 2 Dayeuhkolot, yang diberikan perlakuan dengan media audio visual memiliki rata-rata 19,20 dengan nilai minimal 13 dan maxsimal 28 yang berarti keterampilan siswa tersebut adalah Baik. 


\section{Pengujian Persyaratan analisis data}

\section{Uji Normalitas}

Setelah diketahui skor rata-rata dan simpangan baku dari variable tersebut maka langkah selanjutnya adalah melakukan uji normalitas. Uji normalitas data digunakan untuk mengetahui data berdistribusi normal atau tidak. Uji statistik yang digunakan adalah uji Kolmogorov-Smirnov dengan taraf signifikan 0,05 karena data yang digunakan dalam penelitian ini berskala ordinal dengan subjek penelitian $\geq 30$ (Ruseffendi, 2010) yang berguna untuk menguji apakah suatu sampel berasal dari suatu populasi berdistribusi normal atau tidak dengan kriteria pengujiannya adalah:

$\mathrm{H}_{0}=$ Data sampel berasal dari populasi berdistribusi normal.

$\mathrm{H}_{1}=$ Data sampel berasal dari populasi berdistribusi tidak normal.

Kriteria pengujiannya sebagai berikut:

Jika nilai Sig. $>$ 0,05 maka $\mathrm{H}_{0}$ diterima.

Jika nilai Sig. $\leq 0,05$ maka $\mathrm{H}_{0}$ ditolak.

Berikut adalah tabel hasil uji normalitas data tes kemampuan memukul shuttlecock smash bulutangkis dengan menggunakan IBM SPSS Statistic 23.

Tabel 2. Uji Normalitas Data Test Keterampilan Smash Bulutangkis.

\begin{tabular}{cccc}
\hline & \multicolumn{3}{c}{ Kolmogorov-Smirnov } \\
\cline { 2 - 4 } & $\begin{array}{c}\text { Statisti } \\
\text { c }\end{array}$ & Df & Sig. \\
\hline Nilai Siswa & .131 & 40 & .082 \\
\hline
\end{tabular}

Berdasarkan pada Tabel 2. tersebut terlihat pada uji normalitas dengan KolmogorovSmirnov hasil tes signifikan $0,082 \geq 0,05$. Nilai tersebut memenuhi kriteria pengujian Sig. $\geq 0,05$ maka $\mathrm{H}_{0}$ diterima artinya data sampel berasal dari populasi berdistribusi normal.

\section{Pengujian Hipotesis}

Pengujian hipotesis dilakukan dengan menggunakan One Shoot Case Study yaitu melihat nilai yang didapatkan dengan jumlah sempel 40 orang siswa, dimana nilai persentase untuk tiga orang siswa 7,5\% baik sekali, dua puluh tiga siswa dengan persentase $57,5 \%$ baik dan empat belas siswa dengan persentase 35\% cukup. Adapun hasil rubik data yang di peroleh dapat di lihat dalam diagram Tabel 3 dan diagram Gambar 3.

Tabel 3. Hasil Data Penilaian Keterampilan Smash Bulutangkis

\begin{tabular}{ccccc}
\hline No & Interval & $\mathbf{N}$ & $\mathbf{\%}$ & Keterangan \\
\hline $\mathbf{1}$ & $80-100$ & 3 & $7,5 \%$ & Baik Sekali \\
\hline
\end{tabular}




\begin{tabular}{ccccc}
\hline $\mathbf{2}$ & $66-79$ & 23 & $57,5 \%$ & Baik \\
\hline $\mathbf{3}$ & $56-65$ & 14 & $35 \%$ & Cukup \\
\hline $\mathbf{4}$ & $41-55$ & 0 & & Kurang \\
\hline $\mathbf{5}$ & $0-40$ & 0 & & Kurang Sekali \\
\hline & Jumlah & 40 & $100 \%$ & \\
\hline
\end{tabular}

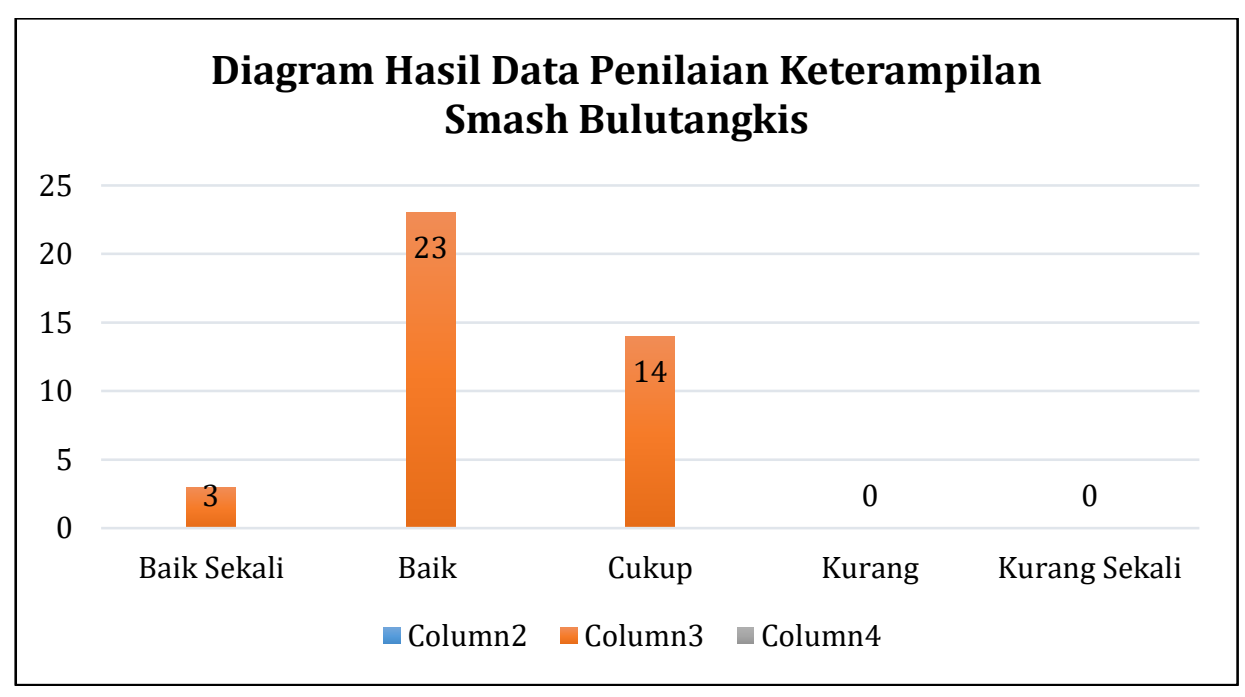

Gambar 3. Diagram Hasil Data Penilaian Keterampilan Smash Bulutangkis

Dari data yang di dapatkan di diagram Gambar 3. dapat dilihat dimana persentase dengan nilai tertinggi $57,5 \%$ baik, 35\% cukup sedangkan 7,5\% sangat baik dan tidak ada yang mendapatkan nilai kurang ataupun kurang sekali. Adapun hasil pengujian hipotesis disajikan dalam bentuk persentase yang dapat dilihat dalam diagram Gambar 4.

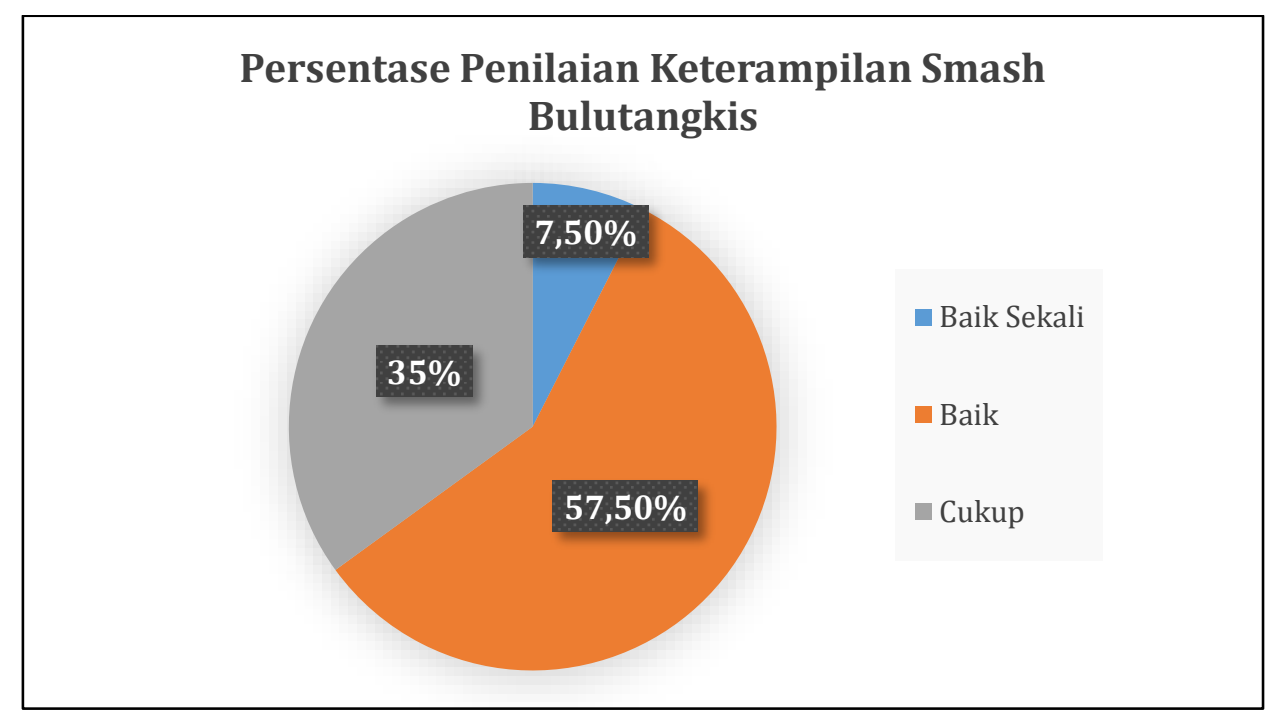

Gambar 4. Diagram Persentase Penilaian Keterampilan Smash Bulutangkis 
Berdasarkan diagram gambar 4. dapat dilihat bahwa persentase dengan nilai terbesar $57,50 \%$ siswa dapat melakukan pembelajaran smash bulutangkis dengan baik. Dengan demikian dapat disimpulkan bahwa penggunaan media audio visual memberikan pengaruh yang baik terhadap keterampilan smash dalam pembelajaran bulutangkis pada siswa SMP Negeri 2 Dayeuhkolot Kabupaten Bandung.

\section{PEMBAHASAN}

Pembelajaran menggunakan media audio visual memberikan pengaruh kepada keterampilan smash dalam pembelajaran bulutangkis di kelas yang di lakukan penelitian, yang mana pengaruh tersebut dapat mempengaruhi kemampuan siswa dalam keterampilan Smash bulutangkis. Berdasarkan hasil penelitian yang dilakukan dapat di ambil kesimpulan bahwa terdapat pengaruh keterampilan siswa dalam melakukan smash bulutangkis dengan nilai yang dapat terlihat dari nilai rata-rata one shoot case study kelas IX-J yaitu 19,20 atau biasa disebut juga 60\% kemampuan siswa dalam pembelajaran keterampilan smash bulutangkis baik. Dalam penggunaan media audio visual pembelajaran dapat mempengaruhi terhadap keterampilan smash dalam pembelajran bulutangkis. Hal ini sejalan dengan penelitian-penelitian yang telah dilakukan berkaitan dengan menggunakan media audio visual.

Hasil dari berbagai penelitian tersebut mengatakan bahwa penggunaan media audio visual dapat mempengaruhi keterampilan yang signifikan terhadap hasil belajar teknik smash dalam pembelajaran bulutangkis (Gustiandaru, 2013). Penerapan Media audio visual memberikan efektivitas yang signifikan terhadap keterampilan teknik dasar bulutangkis mahasiswa Penjaskesrek Universitas Islam Riau dimana hasil akhir lebih besar dari pada tes awal (Cendra et al., 2019). Penerapan media audio visual dalam pembelajaran merupakan metode mengajar yang efektif, karena media audio visual dapat menggabungkan beberapa komponen gambar, video dan suara menjadi satu kesatuan, sehingga meningkatkan minat dan memperkuat pemahaman siswa pada materi pembelajaran teknik Smash bulutangkis. Penggunaan media audio visual memberikan Peningkatan yang signifikan terhadap peningkatan teknik servis pendek backhand ekstra kurikuler bulutangkis siswa putra SMP Intan Permata Hati Surabaya, sebesar 41,75\% (Setiawan, 2014).

\section{KESIMPULAN}


Berdasarkan hasil analisis data penelitian yang penulis teliti terbukti bahwa maka bahwa penggunaan media audio visual memberikan pengaruh terhadap keteranpilan smash dalam permainan bulutangkis kelas IX-J di SMP Negeri 2 Dayeuhkolot Kabupaten Bandung.

\section{DAFTAR PUSTAKA}

Cendra, R., Gazali, N., \& Dermawan, R. . (2019). Efektivitas media pembelajaran audio visual terhadap keterampilan teknik dasar bulu tangkis. Jurnal Sportif, $v$. Https://ojs.unpkediri.ac.id/index.php/pjk

Gustiandaru, R. T. (2013). Pengaruh Penggunaan Audiovisual Terhadap Peningkatan Keterampilan Smash Dalam Permainan Bulutangkis Pada Siswa Kelas Xi SMA PGII 2 Bandung. Repository.Upi.Edu.

Hambali, S. (2018). Penggunaan media modifikasi dalam pembelajaran s. Jurnal Seeed (Seport, Physical Education, Empowerment), 1(1), 65-74.

Juliantie, T., Subroto, T., \& Yudiana, Y. (2012). Belajar dan Pembelajaran PENJAS. UPI Press.

Muhson, A. (2010). Pengembangan Media Pembelajaran Berbasis Teknologi Informasi. Jurnal Pendidikan Akutansi Indonesia, 8(2).

Nurhasan. (2013). Tes dan Pengukuran Dalam Pendidikan Jasmani. STKIP Pasundan.

Setiawan, A. (2014). Penerapan media audio visualterhadap peningkatan teknik servis pendek backhand ekstrakurikuler bulutangkis siswa putera smp intan permata hati surabaya (Studi pada Siswa Putera SMP Intan Permata Hati Surabaya ). Jurnal Pendidikan Olahraga Dan Kesehatan, 2.

Sobarna, Akhmad. Aditya Prasetyo, dicky Gunawan, S. P. C. (2016). Jurnal Olahraga. Penggunaan Media Ular Tangga Untuk Keterampilan Dasar Bermain Bola Basket, 2(2).

Subarjah, H. (2010). Hasil belajar keterampilan bermain bulutangkis studi eksperimen pada siswa diklat bulutangkis fpok-upi. 325-340.

Sugiyono. (2015). Metodologi Penelitian Kuantitatif Kualitatif dan R\&D. Alpabeta. 